\title{
Una reivindicación de la conciencia (De la crítica a la filosofía de la conciencia a la reivindicación de la conciencia moral)
}

\author{
CARlos Gómez \\ UNED, Madrid
}

\begin{abstract}
RESUMEN. La «filosofía de la conciencia» constituye el paradigma fundamental de la filosofía moderna de Descartes a Kant. Dicho paradigma ha sido sometido a sucesivas críticas, en primer lugar por parte de la denominada «filosofía de la sospecha» y, más tarde, por «el giro lingüístico», aquí considerado desde la perspectiva de la ética discursiva habermasiana. Aunque esas críticas obligan a romper la primacía y el monologismo de la «filosofía de la conciencia», no deberían llevar a olvidar el valor de la conciencia (moral) misma, por resituada que quede. Así se trata de defender siguiendo los planteamientos de, entre otros, Wellmer, Muguerza, Bilbeny o Renaut, y reconsiderando desde ese horizonte la confrontación entre Hegel y Kant, retomada en nuestros días por la existente entre comunitaristas y liberales, para, finalmente, esbozar algunas perspectivas sobre la relación entre individualismo y cosmopolitismo.
\end{abstract}

Palabras clave: «Filosofía de la conciencia»; «filosofía de la sospecha»; giro lingüístico y ética discursiva; resituación y valor de la conciencia (moral); Hegel versus Kant; comunitarismo y liberalismo; individualismo y cosmopolitismo.
ABSTRACT. The "philosophy of conscience» is the fundamental paradigm of modern philosophy from Descartes to Kant. Such paradigm has been the object of continuous criticism starting with the so call «philosophy of suspicion» and latter on by the «linguistic turn», which in this article is considered from the perspective of the discursive ethics of Habermas. Although these criticisms force us to abandon the primacy and the monologism of the «philosophy of conscience», we should not forget the value of the moral conscience itself in spite of all its resituations. This is what I try to claim in this work, following the arguments of Wellmer, Muguerza, Bilbeny or Renaut, among other critics, and revisiting, from this perspective, the confrontation between Kant and Hegel, which has been brought up again by the liberal/communitarian debate, leading finally my discusion to the relation between individualism and cosmopolitanism.

Key Words: «Philosophy of conscience»; «philosophy of suspicion»; linguistic turn and discursive ethic; resituation and value of the (moral) conscience; Hegel versus Kant; communitarism and liberalism; individualism and cosmopolitanism.

El tema de la conciencia moral que voy a abordar en este artículo resume en sus líneas básicas un trabajo de investigación más amplio, por lo que algunos aspectos no podrán desarrollarse y aparecen sólo apuntados, aunque el texto puede leerse de forma autónoma. En todo caso, el tema podría enfocarse des- 
de puntos de vista muy diferentes al que yo mantendré aquí, pues, como trabajo de investigación abierto, no trato de agotar todas las perspectivas y ni siquiera en las adoptadas cerrar los temas debatidos - a pesar de que no falten, como veremos, pronunciamientos al respecto. Por citar sólo dos de esas perspectivas en las que, aunque ricas, no entraré ahora, se pueden tener en cuenta, por ejemplo, la de Daniel Dennett en La conciencia explicada (Dennett, 1995), con la que discute John Searle en su estudio El misterio de la conciencia (Searle, 2000; cf. también, Searle, 1992, 266 ss.), o la línea de psicología moral, de Piaget a Kohlberg, a la que me he referido, sin embargo, en alguna ocasión (Gómez, 1994a) y que, entre nosotros, ha estudiado con detención José Rubio Carracedo (Rubio Carracedo, 1987, 103-218; 2000, 17-63). Con todo, la tarea que tenemos por delante es ya de por sí dilatada y, pese a sus limitaciones, creo que lo importante a este respecto, no es la quimérica pretensión de enunciar todos los lados de una cuestión, sino el que nuestras formulaciones sean lo suficientemente amplias y flexibles, como para poder luego engarzar con otros aspectos u otros lados. Según ya advirtiera Ortega, el punto de vista del Absoluto no sólo es inasequible, sino una pura contradicción, que queriendo ver más se fuerza a no ver nada o a ser ciego. Sin pretender, pues, verlo todo, sólo trataré de arrojar luz sobre algunos flancos y de articular una serie de problemas.

El trabajo se divide en tres partes fundamentales, precedidas de una introducción y seguidas por una coda o epílogo. En la primera de ellas trato de asumir las críticas de la denominada filosofía de la sospecha, que, según se sabe, tiene como principales representantes a Marx, Nietzsche y Freud. La segunda parte incorpora los planteamientos del denominado "giro lingüístico», en particular por lo que se refiere a las éticas discursivas, siguiendo en lo esencial los desarrollos de J. Habermas, en sus caracteres y problemas, así como las críticas efectuadas por diversos autores a sus propuestas éticas. La tercera, en fin, retoma desde esas coordenadas la diatriba - renovada de diversa forma en nuestros días - de Hegel con Kant, pues, aunque por lo indicado, no faltará aquí el punto de vista histórico, mi interés no iba dirigido estrictamente por él, y esta lectura de ida y vuelta -0 , si se quiere, lectura que retoma problemas clásicos desde nuestro horizonte - me parecía más sugerente y fecunda. Esas tres partes van precedidas, como digo, por una introducción en la que artículo algunas de las inflexiones básicas de la moderna filosofía de la conciencia, para concluir con un epílogo en el que se señalan perspectivas por las que la investigación podría abrirse a otros debates y cuestionamientos. 
Una reivindicación de la conciencia (De la crítica a la filosofía de la conciencia a la reivindicación ...

\section{La filosofía de la conciencia, paradigma de la filosofía moderna}

La filosofía moderna puede dejarse englobar, en una de sus líneas fundamentales, bajo el denominado paradigma de la «filosofía de la conciencia», aun cuando lo primero, quizá, que se puede destacar es la pluralidad terminológica con que los diversos autores se refieren a ese conjunto de desarrollos filosóficos - que, inaugurados por Descartes, alcanzan a Kant y, de alguna manera, a Hegel-, pues tan pronto se habla de filosofía de la conciencia como de filosofía de la reflexión o filosofía de la subjetividad, de mentalismo o de monologismo, al destacar, dentro de un aire de familia común, uno u otro de los rasgos considerados más relevantes.

En cualquier caso, y como Habermas, entre otros, ha destacado ( Caminos hacia la destrancendentalización. De Kant a Hegel y vuelta atrás», Habermas, 2002a), el pensamiento moderno supone un giro subjetivizador, en el que se desconfía de la capacidad de nuestra razón para alcanzar el mundo y sus estructuras, habiéndonos de contentar con nuestra idea del mismo. En efecto, en su caracterización del que ahí Habermas denomina paradigma mentalista, el giro ligado a Descartes puede sintetizarse en la pregunta acerca de cómo podemos asegurarnos de la certeza de nuestro saber, lo que condujo a una nueva concepción del mismo, según la cual el sujeto del conocimiento posee representaciones de objetos, siendo el término clave el de «representación, que media entre el sujeto cognoscente y el mundo a conocer» (Ib., 184). Por eso, frente a las preocupaciones básicamente ontológicas de la premodernidad, ahora es la cuestión de la certeza del conocimiento la que cobre la primacía. Y en ella, será la conciencia la que proporcione el punto de partida y el guía por excelencia de la elaboración filosófica. Conciencia ante todo en su sentido epistemológico (Bewusstsein), es decir, en cuanto capacidad para la percatación o reconocimiento de algo exterior o interior, a diferencia de su sentido moral, referido al conocimiento de los valores o del bien y del mal, careciendo el castellano de términos diferenciadores, pero no así el inglés (consciousness, conscience) o el alemán, que hablará para el sentido moral de Gewissen o, a veces, de Moralbewusstsein, como en la obra del propio Habermas Moralbewusstsein und Kommunikatives Handeln. Punto de partida y guía por excelencia, digo, porque la conciencia se ofrece ante todo con la inmediatez de la evidencia a sí misma. Y así, en Descartes, el cogito, no es sólo la certeza de la que no cabe dudar, sino criterio ulterior de toda certeza, alcanzado por la reflexión sobre sí. En efecto, el segundo rasgo caracterizador de ese paradigma sería, según Habermas, el que el sujeto del conocimiento es identificado con el yo, alcanzado por el giro reflexivo sobre mí como alguien capaz de tener representaciones de objetos y capaz de representarse a sí mismo en la autoconciencia. De este modo, se da apertura a una subjetividad denominada interioridad y alcanzada por introspección, la cual otorga al sujeto un acceso privilegiado a sus representaciones; representaciones, que, en lo 
que se refieren al menos a sí mismo, se le presentan como vivencias inmediatamente evidentes, siendo la verdad entendida como tal evidencia subjetiva o certeza.

En ese paradigma habrá, con todo, transformaciones notables. Ya Descartes (Descartes, 1974 y 1979) se encontró con que no podía salir tan fácilmente desde el recinto fortificado del cogito al mundo, pues la claridad y distinción no era - exceptuado el, al parecer, inatacable cogito - criterio suficiente de certeza, habiendo de lanzarse a la aventura de demostrar nada menos que a Dios, que habrá de actuar de garante de nuestras demás ideas claras y distintas, y de nuestros juicios no precipitados; demostración que, como es obvio, no podía partir de los fenómenos del mundo, a los que no se había llegado, sino sólo de la idea de Dios, desde la que se pasa a su existencia en una variante del argumento ontológico. Pero será ese intento de alcanzar cuestiones de hecho por un simple análisis conceptual el que Kant considerará dogmático, por cuanto la existencia no puede ser afirmada por ningún análisis conceptual - aunque fuese infinito-, ya que no es ningún predicado, sino una «posición absoluta», algo absolutamente puesto frente al sujeto (Kant, 1978, A598, B626), de la que sólo cabe cerciorarse a través de la experiencia, cuyas condiciones de posibilidad trata de investigar la Crítica de la razón pura. Pero, instancia crítica y criticada a la vez, como el doble genitivo del título revela, seguimos estando en una filosofía mentalista y monológica de la conciencia y de la reflexión, que quiere evitar los escollos anteriores gracias a un desarrollo trascendental, a un análisis de los elementos y estructuras que hemos de suponer para que la experiencia sea posible, remitiendo finalmente a un «yo pienso», que ha de acompañar necesariamente todas mis representaciones.

Indudablemente, ese «yo pienso» es una herencia cartesiana, aun cuando queda transformada, siendo esa transformación la que permite abrir - como ha subrayado Paul Ricoeur, en De l'interprétation (Ricoeur, 1970, 41) - una brecha entre la filosofía de la conciencia y la filosofía de la reflexión. En Descartes, veíamos, la conciencia de sí pretende ser - pese a la apariencia deductiva de la fórmula Cogito, ergo sum - la constatación de una evidencia inmediata, que es a la vez la posición de un ser y de un acto: existo, pienso; existir, para mí, es pensar; existo en tanto que pienso, y como esta verdad no puede verificarse como un hecho ni deducirse como una conclusión, debe asentarse en la reflexión. Sin embargo, la reflexión puede ser entendida de forma distinta a la pretendida evidencia de la conciencia inmediata, pues si es por reflexión como puedo llegar a captarme, también es cierto que el sí mismo alcanzado se descubre enseguida como algo abstracto y vacío. El Ego del Ego cogito no se ofrece inmediatamente dado, sino que ha de captarse en el espejo de sus objetos, de sus obras y de sus actos, y la reflexión sería entonces contraria a la inmediatez: el Ego ha de ser mediado para salir de su vaciedad, con lo que la conciencia de sí se convierte, no en algo dado, sino en una tarea. Sin 
perjuicio de volver sobre estas cuestiones al final del trabajo, señalemos ahora que, ya en Kant, la apercepción del Yo que acompaña todas mis representaciones no es una intuición sensible ni una imposible, para el hombre, intuición intelectual y, por tanto, tal autoafección de un yo real que le permite a Kant decir «yo existo pensando» no puede convertirse en fundamento para una demostración de la sustancialidad o la inmortalidad del alma, según indica la crítica de los paralogismos de toda psicología racional.

En ese camino, parecería ser Hegel el primero en romper el monologismo de la conciencia y en efectuar el tránsito «del yo al nosotros», pues la Fenomenología del espíritu trata de criticar - según lo acentuó, entre otras, la lectura de H. Marcuse (Marcuse, 1971, 94ss.) - los análisis particularistas del entendimiento (Verstand) (según los cuales podemos conocer diversos objetos aisladamente), merced a la labor de la razón (Vernunft), que descubre las relaciones entre cualidades y objetos presuntamente aislados, así como la mediación del objeto por el propio sujeto, de forma que los primeros capítulos de la Fenomenología suponen el paso de la conciencia a la autoconciencia hasta llegar - en uno de los pasajes más famosos de la filosofía occidentala esa gran parábola de la lucha entre las autoconciencias contrapuestas (Hegel, 1966, 115-121). Frente a la ingenua pretensión de la conciencia aislada, que cree poder afirmarse a sí misma en su inmediatez, Hegel insiste en la necesaria constitución intersubjetiva de la identidad, si es que ésta no ha de quedar ilusoria y vacía, como en la tautología por la que uno pretende captarse a sí diciendo: "Yo soy yo», esto es, embarcándose en ese «callejón sin salida» de «la autoconciencia abstracta inmediata»-por expresarlo con Jean Hyppolite (Hyppolite, 1994, 155) —, que es el discurso del amo. Pero, por más que esa constitución intersubjetiva de la identidad supusiera una importante quiebra en la marcha de la filosofía monológica de la conciencia, Hegel mismo pertenece al paradigma que critica y, aunque lo cuestione en alguno de sus momentos esenciales, no logra salir del marco que exalta en el mismo momento en que lo problematiza, que no en vano la Fenomenología del Espíritu se ofrece como una historia de la dialéctica de la conciencia.

Y así, aunque el propio Habermas ha tratado de consumar el giro del yo al nosotros, siguiendo en ello tanto a Hegel como al sociólogo George Herbert Mead, para hablar, en Pensamiento postmetafísico, de «individuación a través de la socialización» (Habermas, 1990), no ha dejado de reparar en que, si el Hegel del período de Jena parece ir en ese sentido, al insistir en la importancia de las mediaciones trabajo, lenguaje e interacción, acabará por no transitarlo al encontrar en la Conciencia «bsoluta un atajo que lo bloquea (Habermas, 2002a, 211-215).

Habría que esperar, pues, a lo que en su día, con expresión que hizo fortuna, Paul Ricoeur denominó «filosofía de la sospecha», cuyos principales representantes son, como se sabe, Marx, Nietzsche y Freud, para que el primer gran asalto a la filosofía de la conciencia tuviera lugar. 


\section{La filosofía de la sospecha}

En efecto, y para entrar ya en ese asedio, tendríamos que comenzar preguntando: ¿sospecha de qué? Lo que agavilla la obra de autores que tematizan campos tan distintos y dan lugar a elaboraciones tan diferentes es sin duda su intención de cuestionar la validez del discurso consciente, al considerar la conciencia en su conjunto como «falsa» conciencia, que ha de ser remitida a, y desenmascarada por, una estructura subyacente, bien se trate de relaciones socioeconómicas (Marx), de la Voluntad de Poder (Nietzsche) o de una infraestrucutra pulsional (Freud). Si Descartes duda de la apariencia de las cosas, pero no duda de que la conciencia sea tal como se aparece a sí misma, triunfando, pues, de la duda sobre la cosa por la evidencia de la conciencia (Ricoeur, 1970, 33), Marx, Nietzsche y Freud introducen la duda en el recinto de la conciencia y tratan de triunfar sobre la misma a través de una hermenéutica, que no buscará el sentido deletreando la conciencia del mismo, sino descifrando sus expresiones.

Puntuaremos brevemente, en los tres autores citados, esa relación simulado-manifiesto o, si se quiere, oculto-mostrado, con la que la sospecha trata de desenmascarar al ardid, para acabar apuntando a una problemática.

En el «Prefacio» a la Crítica de la economía política, que, al decir de Althusser, vendría a constituir algo así como el Discurso del método de la nueva filosofía, Marx observaba: «En el curso de su vida social, los hombres entran en relaciones de producción, independientes de su voluntad, que corresponden a un estadio definido de desarrollo de las fuerzas materiales productivas. La suma total de esas relaciones de producción constituye la estructura económica de la sociedad, la base real sobre la que se elevan las superestructuras legal y política, y a la que corresponden formas definidas de conciencia social. El modo de producción en la vida material determina el carácter general de los procesos sociales, políticos y espirituales. [Y concluye:] No es la conciencia de los hombres la que determina su existencia social, sino, al contrario, su existencia social la que determina su conciencia» (Marx, 1975, I, 373).

Ese enfoque nos llevaría directamente al problema de la ideología, pues, como indica Ricoeur en Utopía e ideología (Ricoeur, 1989), el que, a diferencia de las utopías, que suelen ser asumidas por sus autores, las ideologías sean siempre negadas por los suyos (ideológica es siempre la posición del otro, nunca la de uno mismo), nos acerca a la cuestión desde el ángulo de la función patológica de la ideología, tal como el concepto fue elaborado por Marx, que es de quien procede el uso más generalizado del término en la tradición filosófica occidental. Función patológica que quizá permita suponer, a contrario, otra posible función constituyente. En cualquier caso, en Marx se podrían distinguir, al menos, dos nociones del mismo: en la Contribución a la crítica de la Filosofia del Derecho de Hegel, en los Manuscritos económi- 
co-filosóficos y en La ideología alemana prevalece la noción de ideología como deformación o distorsión opuesta a la realidad, a la praxis, pues la materialidad de ésta es siempre anterior a la idealidad de las ideas que la reflejan, deformándola, invirtiéndola, tal como de manera eminente sucede para Marx con la religión, que es - con metáfora tomada de la experiencia física o fisiológica de la visión - una «imagen invertida» de la realidad, «el corazón de un mundo sin corazón y el espíritu de una situación carente de espíritu» (Marx, 1984, 94). Pero no es sólo la religión la que procura tales distorsiones. También la filosofía del idealismo alemán, que cree en el poder conformador de ideas desenraizadas de las relaciones sociales en las que se insertan, camina cabeza abajo y es preciso ponerla sobre sus pies. Más tarde, sin embargo, la ideología se opone ante todo a la ciencia, con lo que el campo de lo ideológico se extiende, más allá de la filosofía idealista, a todo enfoque precientífico de la vida social. Esa línea de continua ampliación del concepto habría culminado, por el momento, en el marxismo de Althusser (Althusser, 1969), que trata de poner entre paréntesis toda referencia al individuo y a la subjetividad, simples apelaciones humanistas a desechar en nombre de la ciencia, apelaciones entre las que habría que incluir el marxismo «emocional» y las reivindicaciones éticas del Marx que defiende todavía las aspiraciones del sujeto como persona y trabajador individual, y se centra en nociones típicamente ideológicas, como la de alienación. Tal expansión conceptual provoca, sin embargo, algunas perplejidades, pues si todo discurso representa intereses ocultos, pero a los que nos encontramos sometidos, se plantea la cuestión de cómo elaborar una teoría de la ideología que no sea ella misma ideológica, habiéndonos de preguntar: ¿cuál es la condición epistemológica de un discurso no ideológico?

Como sabemos, esos problemas no escaparon a la percepción crítica de los francfortianos (Gómez, 1995), los cuales hubieron de plantearse, para decirlo con la contraposición del artículo programático de Horkheimer (Horkheimer, 1974), frente a la teoría tradicional, el estatuto epistemológico de la teoría crítica misma, lo que acabó finalmente llevándoles a las aporías de la fundamentación normativa, pues si es cierto que en Marx hay un indiscutible momento kantiano (tal como se expresa ejemplarmente en el dictum de la Contribución a la crítica de la Filosofía del Derecho de Hegel, según el cual la crítica desemboca en "el imperativo categórico de echar por tierra todas las relaciones en que el hombre sea una esencia humillada, esclavizada, abandonada y despreciable»; Marx, 1984, 100), no es menos cierto que, junto a ese «marxismo cálido» - por echar ahora mano de la tipología de Bloch-, que no deja de incitar a la actitud ética del «héroe rojo» en las encrucijadas no aseguradas del camino, el «marxismo frío» albergaba también una considerable, si no mayor, herencia hegeliana por la que la emancipación venía a concebirse como un proceso ineluctable debido a las contradicciones internas del sistema (Bloch, 1977). 
Sea lo que fuere de esos problemas, algo similar para nuestra cuestión, aunque desde una perspectiva muy distinta, volvemos a encontrarlo en Nietzsche. Por referirme sólo a un texto, entre los muchos que podrían aducirse, podemos recordar aquel pasaje de Más allá del bien y del mal, en el que Nietzsche decía: «Lo que nos incita a mirar a todos los filósofos con una mirada a medias desconfiada y a medias sarcástica no es el hecho de que se equivocan y extravían con gran facilidad, de que son muy inocentes, en suma, su infantilismo y su puerilidad, sino el hecho de que no sean suficientemente honestos: siendo así que todos ellos levantan un ruido grande y virtuoso tan pronto como se toca, aunque sólo sea de lejos, el problema de la verdad. Todos ellos simulan haber alcanzado sus opiniones propias mediante el autodesarrollo de una dialéctica fría, pura, divinamente despreocupada, cuando, en el fondo, es una tesis adoptada de antemano, una ocurrencia, una inspiración, casi siempre un deseo íntimo vuelto abstracto y pasado por la criba lo que ellos defienden con razones buscadas posteriormente: de manera que todos ellos son abogados que no quieren llamarse así, y en la mayoría de los casos, incluso, pícaros patrocinadores de sus prejuicios, a los que bautizan con el nombre de "verdades"» (Nietzsche, 1972, 25).

Pero, de nuevo aquí: ¿cómo elaborar una teoría de la verdad que no sea ella misma simple racionalización de deseos e intereses no confesados u ocultos? Y si las aseveraciones de Nietzsche pretenden tener valor de verdad, ¿no habrá de suponerse un cierto grado de autonomía de la razón, frente a la trama de intenciones embozadas y prejuicios en los que habitualmente se ve envuelta, autonomía que sería precisamente la que le habría permitido escapar de tales enredos al propio Nietzsche? Como se ha hecho ver en diversas ocasiones - así, por ejemplo, Olivier Reboul en Nietzsche, crítico de Kant (Reboul, 1993) o Jürgen Habermas en Conocimiento e interés (Habermas, 1982, 286-295) - el valor de la denuncia nietzscheana no logra, sin embargo, evitar las aporías a que conduce una reducción psicologista del problema del conocimiento en general.

Y tal tipo de reducción es el que amenaza sin duda a la estrategia psicoanalítica, amenaza cumplida algunas veces en el propio Freud, muchas en varios de sus seguidores y siempre según una concepción muy difundida del psicoanálisis, que me gustaría combatir tanto por razones filosóficas como psicoanalíticas (Gómez, 1998a y 2002a). Y es que, por mucho que Freud insistiera en la importancia de los procesos inconscientes, como no dejó de hacer, toda su obra es, sin embargo - por peculiares que fuesen los laberintos transitados-, una propuesta de discusión racional. Freud persigue, por decirlo con el título de la obra del año 15, Las pulsiones y sus destinos, no para reducirlo todo a lo sexual (como querría la vulgarizadora lectura pansexualista), sino para mostrar la incidencia de lo sexual en todos los registros - de lo onírico a lo sublime. Es así como se convierte en un auténtico «maestro de la sospecha», al denunciar las ambigüedades de lo ideal o de los mandatos su- 
peryoicos —en buena medida inconscientes, pues la conciencia moral es sólo una de las funciones del superyó-. Pero ese tenaz rastreo genético-funcional no puede sustituir a una crítica sustantiva - de la religión, de la ética, de la estética-, que escapa a la competencia del psicoanálisis, por cuanto ser primero, desde el punto de vista cronológico, no es ser primero, desde el punto de vista de la fundamentación o de la justificación racional.

Y, por lo que a la conciencia se refiere, es preciso insistir en que, por mediada que se encuentre, sigue siendo para Freud una instancia decisiva y central, como no tuvo empacho en subrayar, por ejemplo, en uno de los estudios centrales de su metapsicología, Lo inconsciente, donde la conciencia (Bewusstsein) es concebida como un «progreso» y como la «fase más elevada de la organización psíquica» (Freud, 1973a, II, 2075), conciencia que goza de un cierto grado de autonomía, gracias al cual, agrega, «se hace posible influir en el sistema Ics. desde el sistema Cc., pese a la dificultad de la tarea» (Ib., 2077). Y si la conciencia es, como defenderá más tarde, en El yo y ello (Freud, 1973c), el «núcleo del yo», la división del individuo entre instancias conflictivas y la propia división de la instancia yoica, en buena medida inconsciente, no anulan esa relativa autonomía del yo. De ahí que, siempre que hablo de psicoanálisis, como en general de toda filosofía de la sospecha y del descentramiento de la conciencia, me enfrento a un doble, pero contrapuesto temor: por un lado que no se tomen suficientemente en serio sus aportaciones, como le sucedía al, por otra parte, gran Krafft-Ebing, autor de una famosa Psicopatología sexual, y que ocupaba la presidencia de la Sociedad Psiquiátrica y de Neurología, en una sesión de abril de 1896, en la que Freud pronunció, ante una audiencia profesional selecta, una conferencia sobre la histeria y la seducción, al concluir la cual el presidente sólo comentó: «Suena como un magnífico cuento científico». Pero temo también, y no sé si más, que, cuando se pretende asumir tales aportaciones, el devoto se deslice por la pendiente de un desenmascaramiento que sustituye la antigua metafísica por una metafísica aún más oscura, pretendiendo validez para sus afirmaciones, mas descalificando toda autonomía del discurso, contradicción a la cual nada se puede responder.

Y otro tanto ocurre - según tuve ocasión de sostener con más detalle en Freud y su obra (Gómez, 2002a) - con la conciencia moral, cuyo papel cardinal el psicoanálisis no tiene por qué tratar de negar reductivamente, como sucede tan a menudo cuando, por ejemplo, se trata de reconducir cualquier actitud ética a una forma encubierta de egoísmo, siquiera sea el de buscar la paz de la propia conciencia, como se dice, olvidando que, en la voz de la conciencia, ya se inscriben las demandas sociales a las que es preciso atender. $\mathrm{O}$, de manera similar, al mantener que el altruísmo moral o el amor al otro (objeto sexual, hijos, Humanidad) no son más que una forma de amor a sí o de narcisismo. Pero, dejando aparte las confusas formulaciones al respecto de Erich Fromm, en Ética y psicoanálisis (Fromm, 1953), y ateniéndonos a Freud, por 
ineliminable que el narcisismo primario, resulte, según trató de resaltar (Freud, 1973b), el que no sea posible amar al otro sin amarse a sí, no implica que el amor propio sea ya amor al otro o que el amor al otro no sea más que amor a sí. A costa de destacar similitudes y de rebajar, correctamente, la hinchazón de nuestras idealizaciones (aquéllas por las que se pretende ser sólo «solidaridad» o «puro altruismo»), se acaba por velar diferencias relevantes en una homogeneización confundente. Como confundente es no apreciar u omitir las diferencias entre Francisco de Asís y Al Capone, pongamos por caso, pues, por incuestionable que el narcisismo de ambos sea, las diferencias en su elaboración son tan notables, que supongo que la mayor parte de los humanos preferiría tener tratos con el primero antes que con el segundo (a no ser que uno pertenezca a «la familia», claro).

Si Freud tuvo el mérito de denunciar el simplismo de nuestras imágenes, ayudándonos a descubrir la argucia y los atajos del deseo, oculto a menudo bajo el manto del ideal, no menos simplista y cansina resulta la actitud de quienes, creyendo estar en el rompe y rasga de las cuestiones, se limitan a plantearlas con una unilateralidad de signo contrario, pero no menos esquemática, sustituyendo el pensamiento por consignas. Como Albrecht Wellmer se vio obligado a observar, en La dialéctica de modernidad y postmodernidad (Wellmer, 1993, 87-88), la filosofía del desenmascaramiento total se sigue nutriendo de la misma metafísica racionalista que se propone destruir. Pero, si no olvidamos las diferencias entre realidad y apariencia, veracidad y mentira, violencia y diálogo, autonomía y heteronomía, entonces ya no se puede decir, a no ser en el sentido de una mala metafísica, que la voluntad de verdad no sea más que voluntad de poder, que el diálogo sea violencia simbólica, que el discurso que aspira a la verdad no sea sino terror encubierto, que la conciencia moral no sea sino violencia interiorizada o que el yo autónomo sea una pura ficción. Quienes convierten la crítica psicológica en propuesta afirmativa se contemplan a sí mismos como los propangandistas de una nueva era en la que la retórica ocuparía el lugar del argumento, el poder el de la verdad y la economía de la avidez el de la moral. Pero para todo eso no hacen falta muchos voceros, porque de todo eso tenemos hace mucho bastante.

\section{El giro lingüistico y la dialogización de la ética kantiana}

Quizá se podría pensar que lo que no logró el primer gran asalto a la filosofía de la conciencia lo consiguiera, sin embargo, el denominado por Richard Rorty giro lingüístico (Rorty, 1990), que no incumbe solamente a la filosofía analítica anglosajona, sino que ha acabado por afectar a todas las grandes corrientes del pensamiento de nuestro tiempo, y que, por lo que a ética al menos se refiere, se ha plasmado en el proyecto de una ética comunicativa o discursiva, tal como lo han formulado en lo esencial Karl-Otto Apel o Jürgen Ha- 
bermas. Éticas discursivas que tratan de evitar el irracionalismo emotivista o existencialista, así como las dificultades del trilema de Münchhausen del racionalismo crítico o las aporías a las que se habían visto conducidos los francfortianos de primera generación, a través de una rehabilitación de la razón práctica kantiana, mas superando su monologismo por una nueva filosofía dialógica, que no atendiera sólo a las dimensiones sintáctica y semántica del lenguaje, sino especialmente a su dimensión pragmática o comunicativa, sin tener en cuenta la cual se incurre en lo que el propio Apel denomina «falacia abstractiva» (Apel, 1985 y 1986).

Mas, para concentrarnos en los desarrollos habermasianos - cuyos lineamientos principales diseñaré, para considerar más tarde ciertos aspectos problemáticos y algunas críticas (Gómez, 1995) - , Habermas, como es sabido, trata de escapar de los límites de la filosofía de la conciencia, al distinguir — en buena medida, tras los pasos de la diferenciación weberiana entre Zweckrationalität y Wertrationalität - distintas dimensiones de la racionalidad, entre las que la primacía no le corresponderá a la racionalidad instrumental o técnico-estratégica - pese a responder al legítimo interés del ser humano por el control del mundo objetivado- , sino a la racionalidad comunicativa, que no se rige tanto por la acción orientada al éxito cuanto por la comprensión intersubjetiva (Habermas, 1982). Dimensión comunicativa de la razón que no se reduce a la primera y que incluso tiene la primacía, pues cada vez que argumentamos en serio estamos presuponiendo (a través de las pretensiones de validez - inteligibilidad, veracidad, verdad, corrección - que inevitablemente alzamos) esa posibilidad de llegarnos a entender. De este modo, en el caso de que en nuestra interacción comunicativa se planteen conflictos acerca de la verdad de nuestras creencias o de la corrección de nuestras convicciones morales, esos conflictos no tienen por qué desembocar en la violencia, sino que podrían ser resueltos discursivamente, en la medida en que la racionalidad comunicativa se traslade de la acción al discurso, donde las pretensiones de validez sobre la verdad y corrección de unas y otras pueden ser sometidas a argumentación. Tal discusión habría de desembocar en un consenso, siempre que los participantes se ajustasen a la situación ideal de habla, esto es, aquella en la que todos los afectados gozaran de una posición simétrica para defender argumentativamente sus puntos de vista e intereses, de forma que el consenso resultante no se debiera a ningún tipo de coacción sino sólo a la fuerza del mejor argumento (Habermas, 1985).

Obviamente, Habermas sabe que la situación ideal de diálogo no es la que siempre preside nuestros discursos y, por tanto, que no es un fenómeno empírico, mas, por contrafáctico que sea, opera en el proceso de la comunicación como una suposición inevitable que podemos críticamente anticipar.

Con esos planteamientos Habermas trata de respetar los dos pilares sobre los que se alzaba la ética kantiana, la universalidad de los principios morales y la autonomía de cada uno de los hombres convertidos en legisladores, a través de la trasposición dialógica del imperativo categórico, según la cual, y en 
palabras de Thomas McCarthy, que el propio Habermas ha asumido, «más que atribuir como válida a todos los demás cualquier máxima que yo pueda querer que se convierta en ley universal, tengo que someter mi máxima a todos los otros con el fin de examinar discursivamente su pretensión de universalidad. El énfasis se desplaza de lo que cada cual puede querer sin contradicción que se convierta en una ley universal a lo que todos pueden acordar que se convierta en una norma universal» (McCarthy, 1987, 377).

Ética procedimental que nos proporciona una estructura para la instauración de una normatividad común colegislada, la cual no tendría por qué impedir el pluralismo de formas de vida, pues sobre éstas no se pronuncia, por cuanto - como subrayara en su Ética del discurso - «el postulado de la universalidad funciona como un cuchillo que hace un corte entre "lo bueno" y "lo justo", entre enunciados evaluativos y enunciados normativos rigurosos» (Habermas, 1985, 129). Así, como insiste en una de sus últimas publicaciones, La inclusión del otro (Habermas, 1999, 24), frente a la desconfianza posmoderna hacia el universalismo, por lo que éste puede tener de uniformizador, se trata de instaurar un universalismo desde el que se puedan afrontar problemas comunes, pero sin menoscabo de las diferencias, a las que sería «altamente sensible», sin reducirse por eso a los límites particularistas de una determinada comunidad.

Por otra parte, Habermas renuncia a todo intento de fundamentación última y metafísica, al partir de la pluralidad de cosmovisiones y dar por supuesto el hecho sociológico de «la muerte de Dios», al que, por lo demás, no le prestó la atención de sus predecesores frankfurtianos, sin que por eso falten algunos pronunciamientos al respecto. De acuerdo con ello, Habermas diferencia distintos usos de la razón práctica, tal como lo formula en su estudio «Los usos pragmáticos, éticos y morales de la razón práctica» (Habermas, 1993). El uso pragmático viene a identificarse con los imperativos hipotéticos kantianos y expresa tan sólo un deber relativo, en función del fin que un individuo se proponga, moviéndose por tanto en el marco de la racionalidad técnico-estratégica. Mas, cuando una persona debe valorar, no sólo respecto a inclinaciones casuales, sino poniendo en juego su autocomprensión como persona, el tipo de vida o carácter que quiere desarrollar para alcanzar una vida lograda (elecciones profesionales, vida amorosa, etc.), no sólo pregunta por los medios adecuados a fines dados, sino por el valor de éstos, es decir, por lo bueno, que sería para Habermas el ámbito de las decisiones éticas, normalmente envueltas en el contexto de las tradiciones de una determinada comunidad. Y conforme el sentido de sus actos afecten a otros, no sólo ya en su comunidad, sino a cualquier otro de cualquier comunidad, los conflictos de intereses deberían ser regulados imparcialmente, bajo un punto de vista moral, no meramente evaluativo, sino estrictamente universal y normativo, tal como lo proponía la primera formulación del imperativo categórico kantiano, que Habermas pretende dialogizar. 
A la base de todos esos desarrollos se encuentra, por lo demás, la defensa de una concepción fuertemente cognitivista en ética, lo que no deja de ser problemático, ya que, por otra parte, Habermas acepta la ilegitimidad del paso del ser al deber-ser, cuando insiste en que «la validez normativa de las declaraciones morales no se puede asimilar a la validez veritativa de las declaraciones descriptivas. Unas dicen cómo se comporta el mundo, las otras qué debemos hacer» (Habermas, 1999, 67). Pero, a fin de socavar esta posición, en la que pretende atrincherarse el escéptico negando la posibilidad de fundamentación, Habermas, en «Una consideración genealógica acerca del contenido cognitivo de la moral», no recurre ante todo a las evidencias de autocontradicción realizativas para identificar los presupuestos universales de la argumentación, como había hecho en Diskursethik, sino a la estrategia de «conceptuar la verdad como un caso especial de validez, en tanto este concepto universal de validez se introduce con referencia al desempeño discursivo de pretensiones de validez» (Ib., 69). Con todo, es discutible que esa analogía procedimental sea suficiente para calificar como fuertemente cognitivista el lenguaje moral, pues éste sigue sin llevarnos a algo que pueda ser parafraseado metalingüísticamente en el lenguaje de la «verdad» y la «falsedad», sin que, por otra parte, parezca equiparable la capacidad de ofrecer razones a un cognitivismo fuerte.

Mas, sea de todo ello lo que fuere, y sin negar la fuerza de la construcción habermasiana, no han dejado de alzarse voces críticas frente a algunos momentos de esa construcción. Para empezar por un autor muy cercano a él mismo, Wellmer insistió, en Ética y diálogo, en que, para escapar a las objeciones escépticas, la ética no solamente no precisa del asidero de una fundamentación última (a la que, como hemos visto, Habermas renuncia), sino que tampoco requiere del presupuesto de alcanzar un consenso último. Por decirlo con sus propios términos: «La ética debe sustraerse a la falsa alternativa entre absolutismo y relativismo. El destino de la moral y de la razón no está inexorablemente ligado al absolutismo de los acuerdos definitivos [...]. Estaremos en mejores condiciones para proseguir en el camino trazado por la Ilustración y por el humanismo revolucionario, si prescindimos de algunos de los ideales de la razón; lo cual no significa alejarnos de ella, sino despojarnos de una falsa concepción de la misma» (Wellmer, 1994, 40-41).

Aun reconociendo el aliento emancipatorio que alienta en las éticas discursivas, entre nosotros ha desarrollado detalladamente su crítica Javier Muguerza, quien no ha dejado de insistir en las confusiones a que puede dar lugar la anfibología del término "comprensión» (Verständigung), similar a la que se produce en el castellano «entendimiento», que se refiere tanto al acto de entender como al de llegar a estar de acuerdo, lo que no siempre tiene por qué suceder, por cuanto es posible entender al otro sin llegar a un entendimiento con él, pudiendo el diálogo desembocar en un pacto o compromiso, que canalizaría la violencia sin uniformizar puntos de vista irrecusablemente plurales (Muguerza, 1990, cap. 7). 
Pareciendo responder a esa objeción (o tratando de matizar su propia postura), Habermas ha diferenciado en obras posteriores - así, en su artículo «Racionalidad del entendimiento»- entre «acuerdo» (Einverständnis) y «entendimiento» (Verständigung), al indicar que «un acuerdo (Einverständnis) en sentido estricto sólo se consigue cuando los participantes pueden aceptar una pretensión de validez por las mismas razones, mientras que un entendimiento (Verständigung) también surge cuando uno de ellos ve que el otro, a la luz de sus preferencias y bajo circunstancias dadas, tiene buenas razones -es decir, razones que son buenas para él - para sostener la intención declarada, sin que el otro, a la luz de sus propias preferencias, tenga que hacer suyas tales razones». (Habermas, 2002b, 112). Pero la distinción efectuada por Habermas no se refiere a las proposiciones en las que se discute la corrección de una presunta norma, sino a la diferencia entre manifestaciones de voluntad no insertas en contextos normativos, como imperativos simples o declaraciones de intención, en los que basta con el entendimiento de las razones del otro, y los actos ilocutivos completos, constatativos o normativos, esto es, aquellos sobre los que se discuten las pretensiones de verdad o de corrección, respectivamente, donde el uso del lenguaje sigue orientándose a la consecución del consenso, debido a lo cual, y por lo que a nuestro tema se refiere, la cuestión sigue planteándose en términos similares a los antes recogidos, términos que todavía convendría en algún extremo explicitar.

Pues es debido a ello, en efecto, por lo que, más que en la primera de las formulaciones del imperativo categórico kantiano — que es la que han tratado ante todo de transponer dialógicamente las éticas discursivas - Javier Muguerza ha puesto el énfasis en la segunda de esas formulaciones, la del hombre como fin en sí, a la que prefiere denominar imperativo de la disidencia, porque, sin necesidad de rechazar la regla de las mayorías como procedimiento de decisión política, impediría que cualquier mayoría, por abrumadora que fuere, pudiera alzarse por encima de la conciencia de cada cual. Ese imperativo, pues, no legitima a un individuo para imponer sus propios puntos de vista a una colectividad (como hacen los golpistas o los terroristas), pero sí legitima a los individuos para desobedecer cualquier acuerdo o decisión colectiva que vaya en contra de sus principios, los cuales no pueden ser sometidos a referéndum (Muguerza, 1986).

La cuestión de la obediencia al derecho levantó hace unos años una más o menos acalorada polémica en la que terció buena parte de los profesores de la entonces denominada área de «Filosofía del Derecho, Moral y Política», y en la que yo mismo intervine en su momento, con motivo de la absolución del insumiso Iñaki Arredonda, por parte del juez Calvo Cabello, en el que, ciñéndome a un punto de vista ético - $\mathrm{y}$ frente a la polvareda de acusaciones levantada por su sentencia-, yo no veía otra contradicción que la que pudiera derivarse de sus apellidos (Gómez, 1998b).

Mas, para volver todavía por un momento a las tesis de Javier Muguerza y reempalmar con nuestra cuestión, cabría decir que, con una concepción más 
positiva de la libertad negativa y más negativa de la libertad positiva que la que Habermas mantiene (Muguerza, 1997), en la tensión entre autonomía y universalidad de la que antes hablamos, parece que Javier Muguerza rompe, en este punto al menos, su reivindicada perplejidad — que Elías Díaz califica, no sin ironía, de «firme perplejidad»-, para, acentuando los componentes existencialistas de su Ética, decantarse, en Ética, disenso y derechos humanos (Muguerza, 1998), por el primado de la autonomía, al considerar que la universalidad, más que un punto de partida que idealiza nuestra realidad, sería la realización (si es que alguna vez se realiza) de un ideal.

No seré yo quien recele de ese primado de la autonomía, pues la universalidad de los principios éticos es, hoy por hoy, más un deseo que una realidad, de forma que, nos guste o no, tenemos que partir de lo que, desde un enfoque diferente, en Soi-même comme un autre, Ricoeur ha denominado, con expresión paradójica, «universales potenciales» o «universales en contexto», que sólo el largo encuentro entre civilizaciones puede ir cribando (Ricoeur, 1996; cf. también Ricoeur, 2002, 252-253). Con todo, y como alguna vez se ha dicho, la posición ética de Javier Muguerza entraña riesgos que él sortea gracias a los firmes presupuestos ilustrados en los que se basa - aun cuando tales presupuestos no nos fuercen a ver su obra, según la ha calificado Fernando Vallespín, como una «terapia de optimismo ilustrado» (Vallespín, 1991, 150) - , pero bastaría poner tales presupuestos en cuestión - Nietzsche, por ejemplo, lo hacía-, para que aquellos riesgos salten a primer plano. Suceda así o no en el pensamiento de Muguerza, creo que algo de eso ocurre en una ética como la de J.-P. Sartre, al hacer de la libertad el fundamento de todos los valores (Gómez, 2002c, 34-41). Kant había hablado, más matizadamente, en la Crítica de la razón práctica, de la articulación entre libertad y moral, viendo en aquélla la ratio essendi de la moral, y en ésta la ratio cognoscendi de la libertad (Kant, 2000, A5, nota). Pero la libertad, condición de posibilidad de la moral, no fundamenta todavía los imperativos morales. Para ello es preciso conjugar libertad y razón, como sucede en la voluntad (Wille), a diferencia del mero libre albedrío (Willkür). Aunque no explica por qué, Sartre (Sartre, 1999) parece suscribir el momento de universalidad de los principios morales (el que un hombre, al elegir, «elige por toda la Humanidad»), pero, como se pone de manifiesto en el famoso ejemplo del alumno que va a pedirle consejo, no encuentra otro criterio para la elección moral que la propia inventiva. Y aunque quiere defender su punto de vista de la acusación de irracionalidad, a través de la analogía con la obra de arte (en la moral, como en el arte, hay creación sin tener que inspirarse en reglas establecidas $a$ priori; no por ello es la obra de arte caprichosa), habría que insistir en que, por lo que al dominio moral al menos se refiere, no toda invención nos hace igualmente humanos - que es lo que, para mí, limita a su vez, pese a su interés, la propuesta de la ética del souci de soi del último Foucault (Foucault, 1987 y 1999) - ; de modo que, si tal invención no ha de degenerar en mero 
capricho o arbitrariedad, la libertad ha de ir unida, en efecto, a la razón, esto es, a la capacidad de exponer ante otros razones, que, aun cuando no fuesen finalmente compartidas, deben ser públicamente argumentables.

Como señaló en su día Apel, éste es un problema característico del existencialismo moderno, pues «¿cómo puede hablar la filosofía teórica en general, pretendiendo validez intersubjetiva, sobre lo que es subjetivo y singular por definición?» (Apel, 1985, II, 351). Desde otro punto de vista, y más recientemente, Taylor ha insistido en similares problemas, pues, si hacemos radicar el valor de una elección sólo en la autenticidad del propio sujeto, aquello entre lo que se elige se torna por ello mismo insignificante (Taylor, 1994, 67 ss.). Por lo cual, para que el recurso a la conciencia no degenere en conciencialismo, ha de ir unido - y esto, obviamente, Muguerza no lo objetaría- a ese ejercicio de dar y recibir razones, lógon didónai, en el que la razón se expresa, se tenga o no la razón. Tanto por su génesis, diversamente mediada, como por la interacción social en la que se inserta, la conciencia viene a ser una especie de célula de consejo (Ricoeur, 2002, 255), en la que interactúan diversos personajes, aunque lo que sí resulta en definitiva solitario (pero, no por ello, forzosamente insolidario) es la decisión final que el individuo acabe tomando, y en la que la posibilidad de la falta de acuerdo es una posibilidad siempre abierta, de la que sería peligroso prescindir; por ello, no podemos dejar de reivindicar un momento inexcusable del pretendidamente superado «paradigma de la conciencia», la cual resulta a la postre la instancia última y decisiva de la vida moral.

En su detallado estudio sobre Kant y el tribunal de la conciencia, N. Bilbeny ha defendido asimismo, frente a la inevitabilidad con que Habermas expone el paso de la filosofía de la conciencia al entendimiento comunicativo, la necesidad de defender un tiempo para la conciencia, sin que ello suponga replegarse a ninguna clase de monologismo, pues no ve razón para hacer incompatibles una ética fundada en el diálogo con la modalidad interior del discurso que se activa con el juicio de sí mismo (Bilbeny, 1994, 153; cf. asimismo, Bilbeny, 1992, 29-45).

Y, en fin, algo así ha venido a defender también, en discusión precisamente con Jürgen Habermas, Alain Renaut, no sólo para el caso más problemático del disenso, sino incluso para el del consenso, pues también en éste el resultado de la discusión requiere la aceptación por parte del individuo, si es que no se quiere caer en la banalidad del «se» («se» piensa, «se» dice...) o en alguna de las formas de la «moral cerrada» de Bergson (Bergson, 1996, 64-78). Y este puesto irremplazable del individuo, si no en el cosmos, sí en la ética, es el momento de verdad que a mí me gustaría rescatar del existencialismo sartreano, pues, a no ser al precio de la mala fe (esto es, trocando libertad en facticidad, fuese ésta una facticidad natural, cualquier supuesta legalidad social o incluso el consenso discursivamente alcanzado), el individuo no puede abdicar de su responsabilidad personal, si es que no se quiere recaer en una nue- 
va forma de heteronomía, que, al hacer dejación de la propia libertad, impide por ello mismo la vida moral. Que es por lo que Renaut reivindica asimismo un momento insustituible de referencia «al paradigma kantiano de subjetividad, aun en el contexto de una filosofía de la comunicación basada en el giro lingüístico» (Renaut, 2003, 16). Según el propio Renaut lo expresa: «Incluso cuando ya se ha alcanzado un acuerdo a través de la argumentación dialógica, ¿acaso el mero reconocimiento del carácter decisivo de un argumento no presupone que "yo" lo propongo, y no tiene este compromiso más que ver con mi relación conmigo mismo que con mi relación con otros [...]. Si no fuera así, pensaría en ellos [en los principios] como algo que se me ha impuesto. En tanto no se tomen en consideración las dimensiones de la aceptación y el reconocimiento (que no se refieren a mi relación con otros, sino a la relación reflexiva conmigo mismo como parte en la discusión), estaré en una situación de heteronomía en relación con estos principios» (Ib., 18-20).

\section{Hegel versus Kant. Perspectivas}

Reivindicado así el papel de la conciencia moral, quisiera, replantear desde tal perspectiva la primera gran polémica frente a la ética kantiana, tal y como fue llevada a cabo por Hegel. Polémica reanudada en nuestros días en el multiforme debate entre liberales y comunitaristas (un estudio de conjunto de tal debate y su evolución en Thiebaut, 1992 y 1998; discutí y comenté esas obras en Gómez, 1994b y 1999, respectivamente), y en la que el propio Habermas ha participado, no sólo en ese marco, sino planteando específicamente la cuestión: «¿Afectan las objeciones de Hegel a Kant también a la ética del discurso?» (Habermas, 1991).

La polémica de Hegel con Kant se desarrolla en diversos momentos de su obra, con sus grandes apariciones en diferentes pasajes de la Fenomenología del Espiritu, la Enciclopedia y los Principios de la Filosofía del derecho, que es el texto al que, ante todo, nos atendremos aquí (Hegel, 1988, 197ss.), aunque también se hace presente, en forma más resumida, en sus Lecciones sobre la Historia de la Filosofia, al exponer el pensamiento de Kant (Hegel, 1955, 417 ss.), así como en otros desarrollos, como, por ejemplo, los dedicados a la figura de Sócrates, el cristianismo o la Reforma, en sus Lecciones sobre la filosofia de la historia universal (Hegel, 1997, 456ss., 543ss., 657ss.). Sin pretender hacerme cargo de las múltiples ramificaciones de esa diatriba, querría referirme ante todo a dos de las acusaciones más frecuentes a la ética kantiana, finalizando con el esbozo de unas perspectivas sobre el paso del yo al nosotros y la cuestión del cosmopolitismo, para concluir con una coda sobre la paz.

Brevemente expuesta, la requisitoria hegeliana insistía en el formalismo de los principios morales kantianos, su universalismo abstracto, la impotencia del deber y el rigorismo de la convicción, que no tiene en cuenta las circunstancias 
y las posibles consecuencias de una aplicación descontextualizada de dichos principios (cf., además de los textos de Hegel antes aludidos, Habermas, 1991; Rivera de Rosales, 2004a y 2004b; Valcárcel, 1988). Hegel concede que la reflexión sobre el deber como principio universal de la voluntad autónoma, tal como se reveló en Sócrates por primera vez y fue articulado por Kant, puede trascender la Sittlichkeit o eticidad, las formas de vida encarnadas en una comunidad, según fueron tematizadas en el mundo antiguo por Platón y Aristóteles; por eso, su propuesta de superar la Moralität, la mera moral, en las instituciones del Estado moderno no quería recaer en la premodernidad ni regresar a la moral convencional del grupo, en cuanto las instituciones del Estado recogerían las aspiraciones críticas y universalistas de la moral kantiana, evitando, sin embargo, el repliegue en la pura interioridad, que, privada de contenidos objetivos, carecería de criterios para rebasar su particularidad y se extraviaría en lo arbitrario. Sin embargo, aunque él creyera superada la época del recurso a la conciencia crítica de los disidentes y rebeldes, la historia más reciente, con su secuela de barbarie públicamente encarnada, convierte en fundada la sospecha de que tal reconciliación no habría de lograrse sino al precio de consagrar una forma de vida como utopía cumplida, lo que no haría sino liquidar el ímpetu crítico del deber ser frente al ser ya alcanzado. Por lo que, sin olvidar lo positivo de la crítica hegeliana, en cuanto a la necesaria constitución intersubjetiva de la conciencia y a la necesidad de que el deber ser aspire a encarnarse en la objetividad social, tal recurso a la conciencia crítica parece ineludible, si no se quiere estar a merced de contextos sociales, que la posibilitan, pero también la atan. Como recientemente ha indicado Ricoeur, en Soi-même comme un autre: «Sin dejar de tener en cuenta la impresionante inculpación hegeliana contra la conciencia moral erigida en tribunal supremo desde la ignorancia soberbia de la Sittlichkeit, nosotros, que hemos atravesado los acontecimientos monstruosos del siglo XX, tenemos razones para escuchar el veredicto mucho más abrumador, pronunciado por las víctimas. Cuando un pueblo es pervertido hasta el punto de alimentar una Sittlichkeit mortífera, el espíritu deserta de instituciones criminales y se refugia en la conciencia moral de un pequeño número de individuos, inaccesibles al miedo y a la corrupción. ¿Quién se atrevería a calificarlos de alma bella, cuando son los únicos que quedan para atestiguar contra los denominados héroes de la acción?» (Ricoeur, 1996, 278).

Pero uno de los cargos más frecuentes es que la moral kantiana - como se declara desde la apertura misma de la Fundamentación - es una moral de la buena voluntad y de la mera intención, que se desentiende de las consecuencias. Es decir, el punto de vista hoy recogido en el dicho de que «la intención es lo que cuenta»; aunque quizá conviniese no hacer mucho caso al refranero, ya que sus máximas son contradictorias y también en él podemos encontrar aquélla según la cual «de buenas intenciones está empedrado el infierno». Fue, en todo caso, Max Weber, quien, en «La política como vocación» (Weber, 1967), efectuó una famosa contraposición entre Gesinnungset- 
hik (ética de la intención, de la convicción o de los principios) y Verantwortungsethik o ética de la responsabilidad. La primera la asimila a la ética kantiana o a la expresada en el Sermón de la Montaña, las cuales, según Weber, se moverían sólo por principios incondicionados, con independencia de las consecuencias derivadas de su acción, conforme al lema: «Obra bien y deja el resultado en manos de Dios» o, de un modo más rigorista: Fiat iustitia et pereat mundus. El político, en cambio, aun cuando no carezca de principios, ha de estar atento a las consecuencias previsibles e incluso no deseadas de su acción, conforme a una ética de la responsabilidad. Si la ética de la convicción resulta "acósmica» y políticamente inoperante, la ética de la responsabilidad desliza, en cambio, al político por la peligrosa pendiente de la violencia y el mal, pues, para Weber, «ninguna ética del mundo puede eludir el hecho de que para conseguir fines "buenos" hay que contar en muchos casos con medios moralmente dudosos y con la posibilidad e incluso la probabilidad de consecuencias laterales moralmente malas [... Por eso, enfatiza finalmente:] Quien se mete en política, es decir, quien accede a utilizar como medios el poder y la violencia, ha sellado un pacto con el diablo» (Ib., 165-168).

Sin embargo, como ha señalado, entre otros, José María González (González, 1985), quizá el dilema weberiano sea, en el fondo un falso dilema. Es cierto, desde luego, que, desde las primeras páginas de la Fundamentación, Kant insiste en que no hay nada que pueda considerarse bueno sin restricción a no ser una buena voluntad. Tal insistencia en la intención, en la incondicionalidad de los principios o en las propias convicciones no se desentiende, sin embargo, de los fines moralmente deseables, subrayando, pocas páginas después, que, para su consecución, se ha de hacer «acopio de todos los recursos al alcance»; sólo que, cuando quiere analíticamente destacar en qué reside la moralidad de la acción, no puede atender al resultado, pues al valor de una buena voluntad «nada puede añadir ni mermar la utilidad o el fracaso» (Kant, 2002, A3). El no tener éxito en una acción que estimamos deseable o debida, puede ser desastroso, ya se trate de salvar la vida de un indefenso ahogándose o de impedir el desencadenamiento de la guerra de Irak; pero ese mal desenlace en nada afecta a la moralidad de nuestra acción. Y que, pese a la importancia de calcular las consecuencias, un político honrado ha de regirse asimismo por principios, lo subraya el propio Weber, al estimar «infinitamente conmovedora la actitud de un hombre maduro (de pocos o muchos años, que eso no importa), que siente realmente y con toda su alma esa responsabilidad por las consecuencias, pero que al llegar a un cierto momento dice: "No puedo hacer otra cosa, aquí me detengo"»», (Weber, 1967, 176) aferrándose a sus principios, como hizo Lutero en las negociaciones de la Dieta de Worms, al exclamar: Hier stehe ich und kann nicht anders.

De ser ello así, no se trataría tanto, según se ha insistido en diversas ocasiones, de dos tipos de ética, cuanto de las nunca fáciles relaciones entre ética y política, las cuales pueden oscilar entre el «alma bella», que preserva la limpieza de sus manos a costa del escapismo o que se convierte en fanática, y la presunta- 
mente eficaz, pero sin escrúpulos, que sacrifica al dios de la violencia principios y personas. Weber tendió a concebir esas relaciones de una manera trágica, pues veía cómo facilmente el político se aliaba con el diablo, pero quizá quepa concebirlas también, sin diluir por ello las tensiones, de una manera dramática, según propuso entre nosotros Aranguren en Ética y política (Aranguren, 1995).

Aunque los ejemplos de Kant no son siempre lo más acertado de sus exposiciones - como la realizada en Sobre un pretendido derecho a mentir por filantropía (Kant, 1993) - , creo desafortunado interpretar el énfasis en la intención como clave de la moralidad de una manera rigorista, según se hace al insistir en el dicho, acogido por el propio Kant: Fiat iustitia et pereat mundus, que sería una manera hiperbólica de expresar que el seguimiento de la ley moral no puede estribar en el cálculo de las pérdidas o las ganancias, más que el intento de establecer una justicia que puede acabar destruyendo el mundo sobre el que precisamente habría de reinar o que fuese indiferente al propio curso del mundo. Según ha insistido J. Rivera de Rosales (Rivera de Rosales, 2004a) y se puede leer en La religión dentro de los límites de la mera razón, a la razón «no puede serle indiferente la cuestión de qué saldrá de nuestro obrar bien, y hacia qué podríamos dirigir nuestro hacer y dejar de hacer para concordar con ello», puesto que, subraya poco después, el hombre moral «quiere que un mundo en general exista y que se haga el bien más alto posible para nosotros»(Kant, 2001, 20-21). Así, no es la justicia ni el apoyar a los seres en sus pretensiones racionales la que lleva implícita la destrucción del mundo, pues el mundo que puede o debe perecer con la acción justa es el mundo del criminal. Esto es, y como el propio Kant interpretará en La paz perpetua el famoso dicho, calificado por él mismo de «un tanto rimbombante», aunque después se le haya tratado de endosar en sus peores aspectos: «La frase, algo rimbombante y que se ha hecho proverbial, pero que es verdadera, fiat iustitia, pereat mundus, puede traducirse al alemán así: "Reine la justicia y húndanse todos los bribones que hay en el mundo"» (Kant, 1985, 57).

Dejando ahí esa cuestión, el segundo de los reproches al que prometí referirme es el que le acusa de defender una idea abstracta del hombre, desenraizado de sus nexos sociales, puesto que nunca nos encontramos con algo así como «el hombre», sino con «hombre concretos», formados en el seno de diversas comunidades y contextos socioculturales. Pero, en Kant, la idea de Humanidad (Menschheit) no es tanto un concepto ontológico y distributivo cuanto un concepto moral, y de ahí, como tuvimos ocasión de observar y el propio Kant subraya en el libro tercero de la Fundamentación, que se pueda atribuir dignidad incluso al malvado, pues, más allá de su comportamiento empírico, su dignidad se basa en su autonomía, en la capacidad de los hombres de autolegislarse - y así, obrar, no sólo conforme a leyes de la naturaleza, sino también conforme a la representación de leyes que cada uno de ellos se da a sí mismo-. Y es esa humanidad común, que alza al hombre por encima de todas las cosas, la que exige respetar a cada una de las personas o indi- 
viduos, no tanto por sus diversas concreciones sociohistóricas, sino ante todo y precisamente en cuanto hombre, en cuanto ser humano.

Tal grado de abstracción no tiene por qué impedir el reconocimiento de las diferencias, como tampoco imposibilitar el denominado paso del «yo al nosotros». Como recientemente ha indicado Javier Muguerza en «Del yo (itrascendental?) al nosotros (¿intrascendente?)» (Muguerza, 2004), aunque la estirpe de tal lema es ante todo hegeliana, no es del todo ajena al propio Kant, sólo que en él no se trataría tanto del paso «de la moralidad individual a la eticidad», «del individuo ilustrado a la comunidad romántica» $\mathrm{u}$ otras posibles formas de entenderlo, sino que estribaría sobre todo - según ha señalado ese excelente conocedor de Kant que es José Gómez Caffarena, al que el propio Muguerza remite en este punto- en el tránsito «Del yo de la pura apercepción al nosotros del reino de los fines» (Gómez Caffarena, 1983). Tomando como punto de partida la famosa conclusión de la Crítica de la razón práctica, Caffarena resalta el carácter radicalmente antropocéntrico de la misma, puesto que es el ser humano el que se siente a la vez solicitado por el espectáculo contrapuesto del cielo estrellado y de la ley moral. Contraposición en la que, por mi parte, creo no sería difícil encontrar - aunque Kant no lo cite - un eco de Pascal, para el que, en formulación muy concisa, pero similar, «por el espacio inmenso el universo me envuelve y me devora como un punto, pero por el pensamiento le envuelvo yo a él» (Pascal, 1981, frag. 113), hasta el punto de que no estimo desacertado decir que si Rousseau puede ser considerado, respecto a Kant, como el Newton de la moral, Pascal podría ser tenido, a su vez, por el Rousseau de la filosofía kantiana de la religión, lo que de algún modo vendría a corroborar la tesis mantenida en su día por Lucien Goldmann en Le Dieu caché (Goldmann, 1986). Siendo quizá esa genealogía la responsable, en buena medida, del tono existencial que Caffarena, por su parte, advierte en la declaración kantiana, al subrayar que, en efecto, el cielo estrellado y la ley moral se le presentan enlazados, dice Kant, «con la conciencia de mi existencia», lo que permitiría evitar el escollo de una interpretación puramente psicologista del yo pienso kantiano, sin necesidad por ello de reducirle a ser una pura función lógica, recluyéndole en el reino - un tanto inoperante, desde el punto de vista moral - de la trascendentalidad. No cabe duda de que, como insiste Caffarena, todos los pasajes en los que Kant se refiere al tema, son un tanto oscuros: el yo del «yo pienso que ha de acompañar necesariamente todas mis representaciones» no es desde luego el «yo» objeto de nuestra experiencia interior, siempre fenoménico, sino que se nos da como resultado de una misteriosa autoafección del yo real, aunque de ese aspecto del yo no cobremos ningún conocimiento determinado - que requeriría la aplicación de las categorías a los datos de la intuición sensible- - Sin embargo, no faltan expresiones de realidad, de existencia (Existenz, es el término habitual de Kant en estos pasajes), pues es preciso presuponer un yo real en la base del yo fenoménico de la experiencia interna, con la característica única de hacerse por sí mismo consciente al hacer unificadamente presentes a la conciencia los datos de la intuición; de este modo, «no 
hay (contra la tendencia espiritualista cartesiana) autoconciencia sin heteroconciencia, pero la autoconciencia es, en todo caso, el acceso privilegiado que el hombre tiene a la realidad» (Gómez Caffarena, 1983, 35). Quizá por ello, Kant, luchando con la terminología, dice que, aunque se trate de una «percepción indeterminada» (sólo determinable ulteriormente por la experiencia interna temporal), se trata de «algo real, que está dado y, por cierto, para el pensamiento en general», pero no para el sentido, por tanto, no como fenómeno, aunque tampoco como realidad en sí misma o noúmeno (ya que no cabe hablar en el hombre de una «intuición intelectual», reservada a un posible Entendimento Arquetípico), sino «tan sólo como algo que de hecho existe» (B422-423, nota). Como él mismo indica (B 157): «En la originaria unidad sintética de la apercepción soy consciente de mí, no como aparezco, tampoco como soy en mí mismo, sino que sólo soy consciente de que soy», realidad que lleva consigo desde luego la idea de sujeto, de simplicidad e identidad consigo, pero de la que no cabe afirmar - como hacía la parologística psicología racional-, que sea sustancial e inmortal, pues no puede garantizarse que su identidad permanente pueda ir más allá de sus presentes condiciones de existencia como sujeto.

Así pues, si el yo de la autoconciencia es un yo real, aunque no reductible al yo discontinuamente fenoménico de nuestra experiencia interna, un yo siempre sujeto y nunca objeto, Kant ha subrayado con ello su carácter individual - no podría ser de otra manera si el pronombre personal de primera persona ha de conservar un mínimo de su significación propia-, pero con ello se plantea el problema de cómo puede ser apto para fundamentar el saber científico, esto es, la objetividad de nuestro conocimiento o, dicho de otro modo, cómo pueden sus afirmaciones ser universalmente válidas. Para ello sería preciso que la objetividad se resolviese en intersubjetividad. Aunque, según Caffarena, tal resolución nunca llegó a ser adoptada por Kant — que más bien basaba esa objetividad en las estructuras trascendentales del conocer humano-, se encaminó mucho más hacia ese paso del yo al nosotros, cuando el sujeto cognoscente - el sujeto, como veíamos, del yo pienso- se autoconcibiese como libre, como auto-nomía, en donde la libertad del autós no es anomia sino que se refiere esencialmente a la ley, al nómos. En esto, Kant prolonga lo ya declararado por Rousseau en El contrato social - que la sumisión a una ley en la que no hubiésemos participado o al impulso del propio apetito es esclavitud, pero seguir la ley que uno se da a sí mismo es libertad (Rousseau, 1980, 27-28) - , pero profundizando la idea rousseauniana de «un gobierno autónomo de los ciudadanos libres de una república», hasta dar con su núcleo ético. Y tal sujeto autónomo es colegislador, asimismo, de un reino de los fines - hacia el que nos conducen las diversas formulaciones del imperativo categórico - en el que, al no tomar ninguno de sus miembros ni a sí mismo ni a otros simplemente como medio, sino al mismo tiempo también como fin, «nace una conjunción sistemática de los seres racionales merced a leyes objetivas comunes» (Kant, 2002, A75). 
Kant es consciente de que tal reino es «sólo un ideal», pero, en cuanto tal, su misión no es tanto describir lo real o idealizarlo cuanto alentar a que lo ideal se realice, es decir, una idea «práctica», si por práctico entendemos — como dice una muy apurada formulación del «Canon» de la Crítica de la Razón Pura- «lo que es posible por libertad» (Kant, 1978, A800, B828). Y cuando esa libertad se orienta, no a las reglas técnico-prácticas (reglas técnicas propiamente dichas o consejos de la habilidad), sino a las leyes práctico-morales (mandatos de la moralidad), alentar a la construcción del reino moral. En función de todo ello, en fin, para Javier Muguerza la consideración de los hombres como seres racionales no haría sino subrayar que es en su condición de tales como forman parte de un mundo inteligible puro, aunque todos ellos forman parte también del mundo sensible, y son por tanto individuos, si bien su carácter de fines en sí no quiere enraizarlo Kant en las diferencias personales que se puedan dar entre los miembros de una comunidad o de diversas comunidades, sino en su capacidad de autolegislarse, que es la que, con independencia de los fines particulares que cada cual siga, nos declara libres e iguales, es decir, fines en sí mismos, que han de ser tomados como sujetos y nunca como simples objetos ${ }^{1}$.

En La modernidad siempre a prueba, Kolakowski observó (Kolakowski, 1990) que si la dignidad o «valor interno» de los hombres, situado a la base de

1 Obviamente, Kant no pudo tener en cuenta las consideraciones críticas de lo que aquí hemos denominado filosofia de la sospecha o del giro lingüístico, y por eso pensamos es preciso recogerlas. Pero con ello no se trata de «restaurar» a Kant, sino de estar atento a la crítica derivada de esos nuevos «paradigmas», sin verse forzado a perder la «inspiración» kantiana — como las éticas discursivas, por ejemplo, no la pierden-, mas sin necesidad de embarcarse en ningún tipo de restauración - y, en cualquier caso, otros tratan de «volver» a A. Smith o a Aristóteles-. En cuanto a la «filosofía de la sospecha», dejando ahora aparte a Marx y a Nietzsche, y por referirme sólo a Freud, es cierto que suele ser más habitual la lectura que los opone que la que los engarza. No seré yo quien niegue las diferencias de tareas y de intención que animan la kantiana patología de la inclinación y la freudiana patología del deber. Pero esas diferencias no deberían llevar - como sucede en las lecturas apresuradas - a una fácil contraposición. A algunos de esos problemas me referí en Freud, crítico de la Ilustración (Gómez, 1998) y he tratado de hacerlo en las consideraciones efectuadas a propósito de la crítica psicoanalítica. Baste ahora, como botón de muestra de lo que insinuo y de una polémica que aquí no se puede desarrollar, con recordar un texto de Freud que creo que a cualquier lector no avisado de quien lo firma le hubiese inmediatamente hecho pensar, más que en él, precisamente en Kant. En Dostoievski y el parricidio, y a pesar del reconocimiento que como «poeta» le brinda, observa: «Cuando se le quiere ensalzar [a Dostoievski] como hombre moral, alegando que sólo quien ha atravesado los estratos más profundos del pecado puede alcanzar el culmen de la moralidad, se olvida algo muy importante. Moral es quien reacciona ya contra la tentación percibida en su fuero interno y no cede a ella. Aquel que, alternativamente, peca y se plantea luego, movido por el remordimiento, elevadas exigencias morales, se expone al reproche de facilitarse demasiado las cosas. Ha eludido el mandato esencial de la moralidad - la renuncia_- pues la observación de una conducta moral es un interés práctico de la Humanidad» (Freud, 1973d, III, 3004). 
los llamados derechos humanos, se hiciese derivar de categorías más específicas que la de la condición humana, tales derechos (que habrá que procurar que no sean simples proclamas, pero eso no se logra liquidándolos, sino tratando de llevarlos a la práctica) se volatilizarían y, con toda probabilidad, el mundo sería mucho más injusto de lo que ahora es, pues ni siquiera habría lugar para el lenguaje tantas veces hipócrita de tales proclamas, sino que pasarían a legitimarse las diversas formas de esclavitud y de imposición de unos hombre sobre otros en función de la pretendida superioridad de alguna de sus diferencias «concretas» (étnicas, nacionales, sexistas, religiosas, de clase, etc.). Al cabo, y como advertía La Rochefoucauld, la hipocresía no es sino el homenaje que el vicio rinde a la virtud (La Rochefoucauld, 1984, frag. 218). Si ésta desapareciese, incluso en el orden de los principios, el vicio y la injusticia podrían presentarse sin ataduras y como el verdadero orden o el orden debido de las cosas. Ha sido muy costoso en la historia alcanzar esas proclamaciones, embrión de unos principios éticos universales, para borrarlas en función de una apología de la diversidad, que, olvidando que es más lo que nos une que lo que nos separa - por mucho que le duela a nuestro narcisismo de clase, étnico o nacional - amenaza con conducir a nuevas e impensables formas de explotación. Y aunque sea cierto que podemos experimentar la solidaridad de manera más intensa cuando quienes la necesitan nos son más cercanos $-\mathrm{y}$ a veces deberemos ejercerla prioritariamente con ellos, pues dependen de nosotros-, tampoco deberíamos dejarnos llevar en exceso por tal sentimiento (como cuando decimos: «(Es que es nuestro paisano o nuestro compatriota!»), pues, arrastrados por él, podemos conculcar deberes más fríos, pero más imperiosos, que nos conciernen (como cuando atajamos cualquier forma de maltrato diciendo simplemente: «iEs un ser humano!»), si es que no queremos caer en las peores formas de mafia o patriotismo, solizarizándonos tan sólo con los que son de «la familia», «como nosotros» o «uno de los nuestros».

Así, el maltrecho «hombre abstracto» de Kant permite conjugar, sin embargo, la defensa de la conciencia individual con el cosmopolitismo o el ideal de una confederación mundial de estados, en la que las relaciones entre los mismos se ajustasen a derecho y no simplemente al estado de guerra existente hasta ahora entre ellos. Es cierto que a tal cosmopolitismo no se arriba sino a través de diversas mediaciones, pues quien no está arraigado, quien no ha aprendido a ser humano en un contexto determinado, probablemente no acierta a serlo en ninguno y, más que cosmopolita, se torna apátrida. Pero quien toma su contexto por el mundo o hace del mismo una trinchera, privilegiando a «los suyos» por encima de los derechos humanos de «los otros», se torna excluyente y tribal, y yugula la humanidad común en función de la exaltación fantaseada y fantasiosa de la propia familia, la ermita local, el terruño o la patria, convertidos entonces - como denunciaba Stanley Kubrick, citando al doctor Johnson, en su magnífica película Senderos de gloria-, en refugio de canallas. 
Kant no se hacía fáciles ilusiones sobre la condición humana y buena prueba de ello son las advertencias vertidas en el primer capítulo de La religión dentro de los límites de la mera razón que lleva el significativo título de «El mal radical en la naturaleza humana». Pero, a pesar de esos negros trazos, mantenía un moderado optimismo, pues, por arraigado que estuviese el mal entre los hombres, pensaba asimismo que se trataba de una propensión, más débil que una más firme disposición hacia el bien, la cual le permitió incluso ligar su admiración por la disposición moral de los hombres con una esperanza de futuro, que él ampliaba hasta la Trascendencia, a fin de añadir, para decirlo con su admirado Rousseau, «el peso de la esperanza al equilibrio de la razón» (Rousseau, 1995, 200).

Mas, poniendo entre paréntesis la cuestión de la Trascendencia, querría enfocar muy brevemente, y ahora sí para concluir, otra de las direcciones a las que se encamina la última de sus grandes preguntas, la de qué nos cabe esperar, cuando se refiere ante todo al futuro intrahistórico de la humanidad. A diferencia de muchos de sus contemporáneos, Kant fue muy cauteloso a la hora de afirmar el progreso moral, así como — según afirma en sus Ideas para una historia universal desde un punto de vista cosmopolita (Kant, 1941) - cualquier pronóstico ajeno a la actuación del propio profeta. Mas, con todo, en esa aproximación asintótica hacia el mundo moral, no desdeñó la posibilidad de una organización mundial de estados sometidos a leyes que habrían de civilizar las relaciones entre los hombres, aun cuando éstos no hubiesen alcanzado un alto grado de moralidad e incluso cuando tales leyes tuviesen que regir - según observa en La paz perpetua - sobre un pueblo de demonios. Como he tratado de hacer ver, tal eticidad encarnada en las instituciones no habría de suponer, sin embargo, la superación de la «mera moral» kantiana, pues la conciencia individual es la única que puede alzarse para exigir una situación mejor o más justa, así como para, llegado el caso, negarse a colaborar o denunciar situaciones tantas veces mortíferas, como, para no ir muy lejos, el pasado siglo y lo que llevamos del presente han mostrado con aterradora amplitud. Resulta, pues, tergiversadora e injusta - pese a tratarse de un artículo bien escrito- la interpretación ofrecida por André Glucksmann en su «Kant en Bagdad» (Glucksmann, 2004), deplorando la realizada por algunos estudiosos alemanes (presumiblemente, Habermas, entre otros), frente a la que él nos quería ofrecer un Kant belicoso, cuando no un legitimador de la invasión de Iraq. Pero es sólo retorciendo el sentido de los textos como se puede hacer de Kant, por decirlo en términos de Juan de Mairena, un hombre de vocación batallona. Mas bien, sin edulcorarse su visión de los hombres ni de los conflictos, él apostó por un camino que nos condujese $\mathrm{Ha}$ cia la paz perpetua (Zum ewigen Frieden) y en sus propuestas cabe enraizar gérmenes de instituciones internacionales (como la ONU o el Tribunal Penal Internacional) enderezadas en ese sentido. $\mathrm{Y}$, sobre todo, aunque estimemos u-tópico, fuera de lugar, esa eu-topía, ese tan bello y buen lugar, lo que kan- 
tianamente sí podemos y debemos hacer es esforzarnos por él sin término, de manera que, aun cuando no fuésemos Hacia la paz perpetua, nos encamináramos Hacia la paz, perpetuamente, que es como el profesor Carlos Pereda (Pereda, 1996) ha propuesto traducir (variando levemente el sentido literal, pero sin traicionar en absoluto su intención profunda) el opúsculo kantiano.

\section{REFERENCIAS CITADAS}

APEL, K.-O. (1985): «El a priori de la comunidad de comunicación y los fundamentos de la ética», en La transformación de la filosofía, trad. de A. CorTinA, J. Chamorro y J. Conill, Madrid, Taurus, II, 341-415.

- (1986): Estudios éticos, trad. de C. DE Santiago, Barcelona, Alfa.

Althusser, L. y E. Balibar (1969): Para leer El Capital, trad. de M. Harnecker, México, Siglo XXI.

Aranguren, J. L. L. (1995): Ética y política, en Obras completas, ed. de F. BlázQuez, Madrid, Trotta, III, 25-166.

BERgSON, H. (1996): Las dos fuentes de la moral y de la religión, trad. e introd. de J. DE Salas y J. Atencia, Madrid, Tecnos.

Bilbeny, N. (1992): Aproximación a la Ética, Barcelona, Ariel.

- (1994): Kant y el tribunal de la conciencia, prólogo de J. L. L. ArANGUREN, Barcelona, Gedisa.

Bloch, E. (1977): El principio esperanza. I, trad. de F. GonZÁlez VicÉN, Madrid, Aguilar, (Reeditado en Madrid, Trotta, 2004).

DennetT, D. (1995): La conciencia explicada. Una teoría interdisciplinar, trad. de S. BALARI, Barcelona, Paidós.

Descartes, R. (1974): Meditaciones metafísicas, trad., prólogo y notas de M. García Morente, Madrid, Espasa Calpe, 2. ${ }^{\mathrm{a}}$ ed.

- (1979): Discurso del método, trad., prólogo y notas de M. García Morente, Madrid, Espasa Calpe, 2. ${ }^{\mathrm{a}}$ ed.

Freud, S. (1973a): Lo inconsciente, en Obras completas, trad. de L. LóPez-Ballesteros, Madrid, Biblioteca Nueva, 3 vols., 3. a ed., II, 2061-2082.

- (1973b): Introducción al narcisismo, en Obras completas, cit., II, 2017-2033.

- (1973c): El yo y el ello, en Obras completas, cit., III, 2721-2728.

- (1973d): Dostoievski y el parricidio, en Obras completas, cit., III, 3004-3015.

Fromm, E. (1953): Ética y psicoanálisis, trad. de H. F. MorcK, México, FCE.

Foucault, M. (1987): Historia de la sexualidad, 2. El uso de los placeres, trad. de M. SolER, Madrid, Siglo XXI, 3. ${ }^{\mathrm{a}}$ ed.

- (1999): Estética, ética y hermenéutica, en Obras esenciales, III, ed. de A. GABILONDO, Barcelona, Paidós.

GimBernAt, J. A., ed. (1997): La filosofía moral y política de Jürgen Habermas, Madrid, Biblioteca Nueva.

Glucksmann, A. (2004): «Kant en Bagdad», El País, 14 de febrero.

Goldmann, L. (1986): El hombre y lo absoluto. Estudios sobre el pensamiento trágico en Pascal y Racine (orig.: Le Dieu caché), trad. de J. R. CAPELla, Barcelona, Edicions 62, 2. ${ }^{\mathrm{a}}$ ed. 
Gómez CAFFarena, J. (1983): «Del yo de la pura apercepción al nosotros del reino de los fines», en El teísmo moral de Kant, Madrid, Cristiandad, 33-43.

Gómez, C. (1994a): «Conciencia moral», en A. Cortina (dir.), Diez palabras clave en Etica, Estella, EVD, 17-69.

- (1994b): «Universalidad, pluralismo e identidad moral. El debate entre comunitarismo y liberalismo. (Entrevista con C. Thiebaut)», Revista Internacional de Filosofía Política, 3, 167-175.

- (1995): «La Escuela de Frankfurt: J. Habermas», en F. VAlLESPín (ed.), Historia de la Teoría política. VI, cit., 219-258.

- (1998a): Freud, crítico de la Ilustración, Barcelona, Crítica.

- (1998b): «Disidencia ética y desobediencia civil», Éndoxa, 10, 387-410.

- (1999): «Tolerancia y complejidad social. (Comentario al libro de C. Thiebaut, Vindicación del ciudadano)», ABC cultural, mayo de 1999.

- (2002a): Freud y su obra. Génesis y constitución de la Teoría Psicoanalítica, Madrid, Biblioteca Nueva - Asociación Psicoanalítica de Madrid.

- (ed.) (2002b): Doce textos fundamentales de la Ética del siglo XX, Madrid, Alianza.

- (2002c): «Problemas de la Ética contemporánea», en GóMEZ, C. (2002b), cit., 7-88.

GONZÁlEZ, J. M. ${ }^{a}$ (1985): «Ética de la responsabilidad y ética de las convicciones», en Memoria académica (1970-1985), Madrid, Instituto Fe y Secularidad, 137-148.

Habermas, J. (1982): Conocimiento e interés, trad. de M. JimÉnez, J. F. Ivars y L. MARTín SANTOS, Madrid, Taurus.

- (1985): «Ética del discurso. Notas para un programa de fundamentación», en Con-

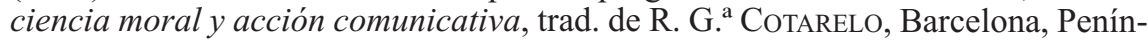
sula, 57-134.

- (1990): «Individuación por vía de socialización. Sobre la teoría de la subjetividad de George Herbert Mead», en Pensamiento postmetafísico, trad. de M. JIMÉNEZ REDONDO, Madrid, Taurus, 188-239.

- (1991): «¿Afectan las objeciones de Hegel a Kant también a la ética del discurso?», en Escritos sobre moralidad y eticidad, trad. e introd. de M. JIMÉNEZ REDONDO, Barcelona, Paidós, 97-130.

- (1993): «Los usos pragmáticos, éticos y morales de la razón práctica», en M. Herrera (coord.), Jurgen Habermas: moralidad, ética y política. Propuestas y críticas, trad. de H. SÄTtele, México, Alianza, 59-78.

- (1999): «Una consideración genealógica acerca del contenido cognitivo de la moral», en La inclusión del otro, trad. G. VILAR, Barcelona, Paidós, cap. 1.

- (2002a): «Caminos hacia la destrancendentalización. De Kant a Hegel y vuelta atrás», en Verdad y justificación, trad. de P. FABRA y L. DíEz, Madrid, Trotta, 181-222.

- (2002b): «Racionalidad del entendimiento. Aclaraciones al concepto de racionalidad comunicativa desde la teoría de los actos de habla», en Verdad y justificación, cit., 99-134.

- (2003): La ética del discurso y la cuestión de la verdad, trad. de R. VILÁ, Barcelona, Paidós. 
Hegel, G. W. F. (1966): Fenomenología del espíritu, trad. de W. Roces, México, FCE.

- (1955): Lecciones sobre Historia de la Filosofia, trad. de W. Roces, México, FCE, 3 vols.

- (1988): Principios de Filosofía del derecho, trad. de J. Vermal, Barcelona, Edhasa.

- (1997): Lecciones sobre la Filosofía de la Historia universal, trad. de J. GAos, Madrid, Alianza, 7. ${ }^{\mathrm{a}}$ ed.

HoRKHEIMER, M. (1974): Teoría tradicional y teoría crítica, en Teoría crítica, trad. de E. Albizu y C. Luis, Buenos Aires, Amorrortu.

Hyppolite, J. (1974): Génesis y estructura de la Fenomenología del Espíritu, trad. de F. FERnÁndez Buey, Barcelona, Península.

KANT, I. (1941): Idea de una historia universal en sentido cosmopolita, en Filosofia de la Historia, prólogo y trad. de E. ÍMAz, México, FCE, 39-66.

- (1978): Crítica de la razón pura, ed. de P. RiBAs, Madrid, Alfaguara.

- (1985): La paz perpetua, presentación de A. TRUYOL y SERRA, trad. de J. ABELlÁn, Madrid, Tecnos.

- (1993): Sobre un presunto derecho de mentir por filantropía, trad. de J. M. Palacios, en Teoría y práctica, ed. de R. Rodríguez Aramayo, Madrid, Tecnos.

- (2000): Crítica de la razón práctica, ed. de R. Rodríguez ArAmaYo, Madrid, Alianza.

- (2001): La religión dentro de los límites de la mera razón, trad., prólogo y notas de F. Martínez MarzoA, Madrid, Alianza.

- (2002): Fundamentación para una metafísica de las costumbres, ed. de R. Rodríguez Aramayo, Madrid, Alianza.

Kolakowski, L. (1990): «¿Por qué necesitamos a Kant?», en La Modernidad siempre a prueba, trad. de J. Almela, México, Vuelta, 66-80.

La Rochefoucauld (1984): Máximas, trad. de E. Benítez, introd. de F. DíEz DEL CORRAL, Madrid, Akal.

Marcuse, H. (1971): Razón y revolución. Hegel y el surgimiento de la teoría social, trad. de J. Fombona, Madrid, Alianza.

MARX, K. (1974): Contribución a la crítica de la Filosofía del Derecho de Hegel, en MarX, K. \& Engels, F., Sobre la religión, ed. de H. Assmann y R. Mate, Salamanca, Sígueme, 93ss.

- (1975): Introducción general a la crítica de la economía política, en K. MARX y F. Engels, Obras escogidas, Barcelona, Fundamentos.

McCARThy, Th. (1987): La teoría crítica de Jürgen Habermas, trad. de M. JiMÉNEZ REDONDO, Madrid, Tecnos.

MuguerzA, J. (1986): «La obediencia al derecho y el imperativo de la disidencia», Sistema, 70 (1986), 27-40. (Recogido asimismo en C. GómEZ, ed. (2002b) 283-307).

- (1990): «Más allá del contrato social: Venturas y desventuras de la ética comunicativa», en Desde la perplejidad. Ensayos sobre la ética, la razón y el diálogo, Madrid, FCE, cap. 7.

- (1997): «De la conciencia al discurso: ¿Un viaje de ida y vuelta?», en J. A. GiMBERNAT (ed.), (1997), 63-110. 
- (1998): «Primado de la autonomía. (¿Quiénes trazan las lindes del "coto vedado"?)», en Ética, disenso y derechos humanos. (En conversación con E. Garzón Valdés), Madrid, Argés. (Previamente había aparecido en R. Rodríguez ARAMAyo, J. Muguerza y A. VAldecantos (eds.), El individuo y la historia. Antinomias de la herencia moderna, Barcelona, Paidós, 1995, 133-154.

- (2004): «Del yo (¿trascendental?) al nosotros (¿intrascendente?). La lectura de Kant en el neokantismo contemporáneo», Daimon, 33, 135-155.

Nietzsche, F. (1972): Más allá del bien y del mal, trad. de A. SÁnchez Pascual, Madrid, Alianza.

Pascal, B. (1981): Pensamientos, trad., introd. y notas de J. Llansó, Madrid, Alianza.

PEREDA, C. (1996): "Sobre la consigna: "Hacia la paz, perpetuamente"», en R. R. Aramayo, J. Muguerza, C. RoldÁn (eds.), La paz y el ideal cosmopolita de la Ilustración. A propósito del bicentenario de Hacia la paz perpetua de Kant, Madrid, Tecnos, 77-100.

Renaut, A. (2003): «Discusión con J. Habermas», en J. Habermas (2003), 15 ss.

Reboul, O. (1993): Nietzsche, crítico de Kant, trad. de J. Quesada y J. LasAGA, Barcelona, Anthropos.

Ricoeur, P. (1970): Freud, una interpretación de la cultura (orig.: De l'interpretation), México, Siglo XXI.

- (1989): Ideología y utopía, trad. de A. L. BIXIO, Barcelona, Gedisa.

- (1996): Sí mismo como otro, trad. de A. NeIRA, Madrid, Siglo XXI.

— (2002): «Ética y moral», en C. GómEZ, ed. (2002b), 241-255.

Rivera De Rosales, J. (2004a): «La moralidad. Hegel versus Kant. I», en M. Álvarez Gómez y M. C. Paredes Martín, La controversia de Hegel con Kant, Salamanca, ed. Universidad de Salamanca, 161-178.

- (2004b): «La moralidad. Hegel versus Kant. II», Éndoxa, 18, 383-416.

Rorty, R. (1990): El giro lingüístico, trad. e introd. de G. Bello, Barcelona, Paidós.

Rousseau, J.-J. (1980): Del contrato social, trad., prólogo y notas de M. ARMiÑo, Madrid, Alianza.

- (1995): Carta sobre la Providencia, en Voltaire-Rousseau, En torno al mal y la desdicha, ed. de A. VILLAR, Madrid, Alianza, 183-208.

Rubio CARRACEDO, J. (1987): «Génesis de la conciencia moral», en El hombre y la ética, prólogo de J. Montoya, Barcelona, Anthropos, 1987.

- (2000): «La psicología moral (de Piaget a Kohlberg)», en Educación moral, postmodernidad y democracia. Más allá del liberalismo y del comunitarismo, Madrid, Trotta, 2. ${ }^{\mathrm{a}}$ ed., 17-63.

SARTRE, J.-P. (1999): El existencialismo es un humanismo, trad. de V. PRACI DE FERnÁndeZ, Barcelona, Edhasa. (Recogido asimismo en C. GómEZ, ed., 2002b.)

SEARle, J. R. (1992): Intencionalidad. Un ensayo en la filosofía de la mente, trad. de E. Ujaldón, Madrid, Tecnos.

- (2000): El misterio de la conciencia. Intercambios con Daniel C. Dennett y David J. Chalmers, trad. de A. DomènECH, Barcelona, Paidós.

TAYLOR, Ch. (1994): La ética de la autenticidad (or.: The malaise of modernity), trad. de P. Carbajosa, introducción de C. Thiebaut, Barcelona, Paidós.

Thiebaut, C. (1992): Los límites de la comunidad, Madrid, Centro de Estudios Constitucionales. 
- (1998): Vindicación del ciudadano. Un sujeto reflexivo en una sociedad compleja, Barcelona, Paidós.

VAlCÁRCel, A. (1988): Hegel y la ética. Sobre la superación de la «mera moral», prólogo de J. MuguerzA, Barcelona, Anthropos.

VALlespín, F. (1991): «Una terapia de optimismo ilustrado», Revista de Occidente, $120,148-156$

- (1995): Historia de la Teoría política. VI, Madrid, Alianza.

Weber, M. (1967): «La política como vocación», en El político y el científico, trad. de F. Rubio Llorente, introd. de R. Aron, Madrid, Alianza, 81-179.

Wellmer, A. (1993): Sobre la dialéctica de modernidad y postmodernidad. La critica de la razón después de Adorno, trad. de J. L. ArÁNTEGUI, Madrid, Visor.

- (1994): Ética y diálogo. Elementos del juicio moral en Kant y en la ética del discurso, trad. de F. Morales, prólogo de M. ${ }^{a}$ Pía LARA, Barcelona, Anthropos. 